\title{
SWIFTLET'S NEST AS POTENTIAL PREBIOTIC COMPOUND FOR THE GUT BENEFICIAL BACTERIA
}

\author{
Abdul Salam Babji ${ }^{* 1)}$, Nur 'Aliah Daud ${ }^{1)}$ \\ 1) Faculty of Science and Technology, Universiti Kebangsaan Malaysia, 43600, Bangi, Selangor, Malaysia \\ Email: daging@ukm.edu.my
}

Submitted 20 February 2021; Accepted 1 March 2021

\begin{abstract}
Swiftlet's clean and edible nest has been consumed for centuries as health food. The benefits of the edible bird nest (EBN) are commonly based on historical and observational reports since its discovery, until some were proven scientifically at recent times. The EBN has a potential to be a prebiotic with the bioavailability of glycan within the EBN. In order to test the prebiotic potential, the EBN glycoprotein and EBN extracted glycan went through a simulated human digestion in vitro test which contained at the level of oral, gastric and small intestine. The undigested components were collected and further tested with simulated in vitro human colon model. The findings showed that the improved growth of beneficial bacteria in the presence of EBN substrates have potentials to provide health benefits. The beneficial group of bacteria may improve and strengthened the host immune system and reducing the risk of pathogenic bacterial infection. These health benefits are crucial especially during the severe health situation such as the pandemic of COVID-19. This study had contributed to the functional properties of the EBN, as a prebiotic for the benefits of consumers and EBN industries. The fundamental of this finding in regards to prebiotic activity can be applied to the area of animal production in the application of prebiotics as value added animal feed ingredients.
\end{abstract}

Keywords: Edible nest; glycoprotein; gut bacteria; immune booster; prebiotic 


\section{INTRODUCTION}

Swiftlets can be found from Nicobar Islands in Indian Ocean to sea caves in the coastal regions of Indonesia, Thailand, Vietnam, Malaysia and Philippines. Swiftlets from the species of Aerodramus fuciphagus construct their nest with glutinous strands of starch-like saliva. The saliva is produced by a pair of salivary glands under their tongue.

The secretion hardens on exposure after the bird has shaped it into a cup-shaped nest. The nest is functioned to protect their hatchlings (Daud et al., 2019a). After the nest was left empty by the young-adult and independent birds, the edible nest was collected and sold either in its original state after harvesting or in processed form after going through cleaning system. With the advancement of food technology, large variety of EBN related products can be found in the market.

Cosmetic industry has been incorporating EBN extract in their products to promote skin cell renewal. Hence, the products were claimed to maintain a youthful, radiant complexion and provides anti-aging effect (Kong et al., 1987; Lim et al., 2002). The major component of this nest that rich in glycoprotein is believed can contribute to variety of biological pathway in order to improve health and well-being. Previous studies have clarified that the EBN possess high medicinal benefits in enhancing skin complexion, stimulating epidermal growth, strengthening immune system, depressing the production of tumour necrosis factor-alpha, inhibiting influenza virus infection, improving respiratory and digestive problems (Daud et al., 2019a). Gut commensal bacteria can impact immune system activity by utilising the undigested compounds from the host, such as dietary fibers and prebiotic, to proliferate and secure the gut from infectious disease (Bailey et al., 2017). Other health benefits from prebiotic consumption may include the relief from poor digestion of lactose, improve immune response, and reduce the risk of diseases such as intestinal disease, cardiovascular disease, non-insulin dependent diabetes, obesity and osteoporosis (Carlson et al., 2018). Prebiotic fibers are derived from plants such as onions, whole grains, garlic, bananas, Jerusalem artichoke and chicory root (Singla and Chakkaravarthi, 2017). However, not all fibers can be source of prebiotic while some could not be used by the gut bacteria.

Prebiotic is described as nondigestible carbohydrate which acts as a food to the selected gut commensal bacteria (Hutkins et al., 2016). Some examples of prebiotics include inulin, fructooligosaccharides, galactooligosaccharides, beta glucan, guar gum, lactulose, isomaltooligosaccharides, xylooligosaccharides, arabinooligosaccharides and others (Carlson et al., 2018). Prebiotic can be applied in a wide range of products in the form of value added ingredients or fat and sugars replacer (Singla and Chakkaravarthi, 2017). The EBN glycans containing hexose, hexosamine and sialic acid have a close proximity with human endogenous glycan and milk oligosaccharide (HMO) which were included as prebiotic compounds. Furthermore, the gut bacteria rely on several bacterial group and species to produce the set of enzymes crucial for the fermentation of these types of glycans (Tailford et al., 2015). Thus, this study is aimed to determine the potential prebiotic of the EBN compound using bacterial mixed culture through in vitro colon model.
*Corresponding author:

Abdul Salam Babji

Email: daging@ukm.edu.my

Faculty of Science and Technology, Universiti Kebangsaan Malaysia, 43600, Bangi, Selangor, Malaysia
How to cite:

Babji, A. S., \& Daud, N. A. (2021). Swiftlet's nest as potential prebiotic compound for the gut beneficial bacteria. Jurnal Ilmu dan Teknologi Hasil Ternak (JITEK), 16 (1), 1-10 


\section{MATERIALS AND METHODS}

\section{Materials}

Edible bird nest (EBN) from Aerodramus fuciphagus was purchased from Mobile Harvester Malaysia Sdn. Bhd. The source of EBN was harvested from swiftlet's houses in Pahang, Malaysia. Other chemicals and enzymes used in this study were purchased from Sigma-Aldrich, USA. In this study, the EBN was soaked in distilled water overnight and further boiled for $30 \mathrm{~min}$ prior further analysis.

\section{Extraction of Glycan from Edible Swiftlet's Nest}

The EBN was soaked in distilled water overnight and further boiled for $30 \mathrm{~min}$. The EBN with concentration of $10 \%$ (w/v) was hydrolysed using $1 \%$ protease enzyme $(\mathrm{w} / \mathrm{w})$ at $\mathrm{pH} 8.0$ to extract glycan from the complex glycoprotein of EBN. The hydrolysis process was performed using a waterbath shaker, with agitation of $150 \mathrm{rpm}$ for $24 \mathrm{~h}$. The hydrolysate obtained was filtered through an ultrafiltration membrane. The remaining solution was collected, freeze and dried. The frozen-dried glycan was stored at room temperature for further analysis.

\section{Quantification of glycan from EBN}

Glycan quantification was done using phenol-sulfuric method according to Dubois et al. (1956). An amount of $50 \mu \mathrm{L}$ sample with concentration of $1 \mathrm{mg} / \mathrm{mL}$ (w/v) was mixed with $150 \mu \mathrm{L}$ sulphuric acid and $50 \mu \mathrm{L}$ of $5 \%$ phenol $(\mathrm{v} / \mathrm{v})$. The mixture was boiled for $5 \mathrm{~min}$. After cooling to room temperature, the absorbance was taken at wavelength $490 \quad \mathrm{~nm}$ using a spectrophotometer (Model UV-160A, Shimadzu, Kyoto, Japan).

\section{Analysis of EBN samples using Nuclear Magnetic Resonance (NMR) Spectroscopy}

The structure of EBN glycopeptide and glycan components was observed using nuclear magnetic resonance spectroscopy
(Model Avance III 600MHz, Bruker). Samples were prepared in Deuterium Oxide $\left(\mathrm{D}_{2} \mathrm{O}\right)$ solvent and hydrogen atom $(1 \mathrm{H})$ analysis was performed for $15 \mathrm{~min}$ per sample.

\section{In vitro digestibility of EBN glycan and EBN glycoprotein}

In vitro digestibility method used was based on Minekus et al. (2014). Digestibility of EBN glycan and boiled EBN in oral phase was tested using simulated salivary fluid, $\mathrm{pH}$ 7.0. The salivary fluid was composed of 3.70 $\mathrm{mM}$ potassium dihydrogen phosphate $\left(\mathrm{KH}_{2} \mathrm{PO}_{4}\right), 15.1 \mathrm{M}$ potassium chloride $(\mathrm{KCl}), \quad 0.15 \mathrm{mM}$ magnesium chloride $\left(\mathrm{MgCl}_{2}\right), 13.6 \mathrm{mM}$ sodium bicarbonate $\left(\mathrm{NaHCO}_{3}\right), 0.06 \mathrm{mM}$ ammonium carbonate $\left(\left(\mathrm{NH}_{4}\right)_{2} \mathrm{CO}_{3}\right), 1.50 \mathrm{mM}$ calcium chloride $\left(\mathrm{CaCl}_{2}\right)$ and salivary $\alpha$-amylase $(150 \mathrm{U} / \mathrm{mL})$. Samples were mixed with $5.0 \mathrm{~mL}$ of the simulated salivary fluid and kept at $37{ }^{\circ} \mathrm{C}$ for 5 min.

Simulated gastric fluid (SGF) was composed of $0.90 \mathrm{mM} \mathrm{KH} \mathrm{PO}_{4}, 6.90 \mathrm{mM}$ $\mathrm{KCl}, 0.10 \mathrm{mM} \mathrm{MgCl} 2,25.0 \mathrm{mM} \mathrm{NaHCO}$, $0.50 \mathrm{mM}\left(\mathrm{NH}_{4}\right) 2 \mathrm{CO}_{3}, 47.2 \mathrm{mM} \mathrm{NaCl}$, $0.15 \mathrm{mM} \mathrm{CaCl} 2$ and gastric pepsin $(4000 \mathrm{U} / \mathrm{mL})$. The simulated gastric fluid was adjusted to $\mathrm{pH} 3.0$ using $1.0 \mathrm{M} \mathrm{HCl}$. Then, the prepared fluid was mixed with the previous oral bolus in equal volume. The mixture was kept at $37^{\circ} \mathrm{C}$ in a shaker for $2 \mathrm{~h}$.

Simulated intestinal fluid (SIF) was composed of $0.80 \mathrm{mM} \mathrm{KH} \mathrm{PO}_{4}, 6.80 \mathrm{mM}$ $\mathrm{KCl}, 0.33 \mathrm{mM} \mathrm{MgCl} 2,85.0 \mathrm{mM} \mathrm{NaHCO}$, $38.4 \mathrm{mM} \mathrm{NaCl}$ and $0.60 \mathrm{mM} \mathrm{CaCl} 2$ and trypsin (based on pancreatin $\alpha$-amylase activity: $100 \mathrm{U} / \mathrm{mL}$ ). The prepared fluid was adjusted to $\mathrm{pH} 7.0$ using $0.1 \mathrm{M} \mathrm{HCl}$ and mixed with previous gastric bolus. The mixture was kept in a shaker at $37{ }^{\circ} \mathrm{C}$ for $2 \mathrm{~h}$. The reaction was terminated by boiling in a water bath for $10 \mathrm{~min}$.

\section{In vitro fermentation of EBN glycan and EBN glycopeptides}

Faecal slurry preparation - Samples from three healthy human volunteers were taken of male gender, aged between 22 and 
26 years old. They were confirmed with no history of gastrointestinal disorder and no records of consuming antibiotics or prebiotic and probiotic supplements for the past 3 months prior to the sampling process. Fresh faecal samples were used as the gut bacterial mixed culture. Phosphate-buffered saline (PBS; $\mathrm{pH} 7.3$ ) was used for dilution in the ratio of 1:10 (w/v) and was homogenised in a stomacher (Stomacher 400, Seward, West Sussex, UK) for 2 min at normal speed (265 rpm) (Sarbini et al., 2011).

Basal medium and fermentation vessel preparation - Fermentation basal medium consists of $0.01 \mathrm{~g} / \mathrm{L}$ calcium chloride hexahydrate $\mathrm{CaCl}^{2} \cdot 6 \mathrm{H}^{2} \mathrm{O}, 0.04 \mathrm{~g} / \mathrm{L}$ $\mathrm{KH}_{2} \mathrm{PO}_{4}, \quad 0.01 \mathrm{~g} / \mathrm{L}$ magnesium sulphate heptahydrate $\left(\mathrm{MgSO}^{4} \cdot 7 \mathrm{H}^{2} \mathrm{O}\right), 2 \mathrm{~g} / \mathrm{L}$ $\mathrm{NaHCO}_{3}, 0.1 \mathrm{~g} / \mathrm{L}$ sodium chloride $(\mathrm{NaCl})$, $0.5 \mathrm{~g} / \mathrm{L}$ L-cysteine hydrochloride, $2 \mathrm{~mL} / \mathrm{L}$ Tween $80,2 \mathrm{~g} / \mathrm{L}$ yeast extract, $0.05 \mathrm{~g} / \mathrm{L}$ haemin, $10 \mu \mathrm{L} / \mathrm{L}$ vitamin $\mathrm{K}, 0.5 \mathrm{~g} / \mathrm{L}$ bile salts and $2 \mathrm{~g} / \mathrm{L}$ peptone water. The basal medium was adjusted to $\mathrm{pH} 7.0$, then $4 \mathrm{~mL} / \mathrm{L}$ of $0.025 \%(\mathrm{w} / \mathrm{v})$ resazurin solution was added and the medium was autoclaved. Sterile customized glass vessels $(100 \mathrm{ml}$; Soham Scientific, Fordham, UK) of stirred batch culture fermentation were set up and filled with a $45 \mathrm{~mL}$ of sterile basal medium, aseptically. The vessels containing basal medium was left gassed with nitrogen gas (15 $\mathrm{ml} / \mathrm{min})$ overnight to create anaerobic conditions (Sarbini et al., 2011).

In vitro colon model fermentation The fermentation was performed in the customized vessels, with controlled temperature, $\mathrm{pH}$ and the continuous supply of nitrogen gas, to imitate the distal part of the colon (Sarbini et al., 2011). The substrates of fructooligosaccharide (FOS) as the positive controls, digested EBN glycan and EBN glycopeptide (the form of EBN after digestion) were added at a concentration of $1 \%(\mathrm{w} / \mathrm{v})$ into each vessel. An amount of $5 \mathrm{~mL}$ of fresh faecal slurry was inoculated in each vessel. The fermentation vessel's temperature was maintained at $37^{\circ} \mathrm{C}$ using circulating water bath. The $\mathrm{pH}$ value was maintained at 6.8 via pH controllers (Fermac 260, Electrolab, Gloucestershire, UK). The fermentation process with constant stirring of the vessels' contents was run for $24 \mathrm{~h}$. Samples from each vessel were taken at $0,6,12$ and $24 \mathrm{~h}$ for bacterial enumeration and short-chain fatty acid analysis.

The experiment was performed in triplicate with faecal slurry from different donors in each experimental replicate. Bacterial enumeration - Synthetic oligonucleotide probes which binds with specific regions of the $16 \mathrm{~S}$ ribosomal ribonucleic acid molecule and labelled with the fluorescent dye cyanine (Cy3) were applied for the specific bacterial groups' enumeration (Table 1). The method of bacterial enumeration was based on Sarbini et al. (2011). An applicable volume of PBS was used to dilute the $10 \mu \mathrm{L}$ of fixed sample volume to obtain around 20-100 fluorescent cell counts in each field of view. About $20 \mu \mathrm{L}$ of the final solution was added into each well of a 6-well polytetrafluoroethylene/poly-L-lysine-coated slide (Tekdon Inc., Myakka City, FL).

Table 1. 16S ribosomal RNA oligonucleotide probes used in the present study

\begin{tabular}{|c|c|c|}
\hline Probe & Specificity & Reference \\
\hline Bif164 & Bifidobacterium spp. & Langendijk et al. (1995) \\
\hline Lab158 & Lactobacillus-Enterococcus & Harmsen et al. (1999) \\
\hline Bac303 & $\begin{array}{l}\text { Most Bacteroidaceae and Prevotellaceae, some } \\
\text { Porphyromonadaceae }\end{array}$ & Manz et al. (1996) \\
\hline Chis 150 & $\begin{array}{l}\text { Most of the bacteria in the Clostridium histolyticum } \\
\text { group (Clostridium clusters I and II) }\end{array}$ & Franks et al. (1998) \\
\hline
\end{tabular}


The samples were left dried for $15 \mathrm{~min}$ in a drying chamber $\left(46^{\circ} \mathrm{C}\right)$ and dehydrated using alcohol dilution series. Hybridisation solution $(50 \mu \mathrm{L}$ consisting of $45 \mu \mathrm{L}$ hybridisation buffer and $5-\mu \mathrm{L}$ probe) was added into each well and left to hybridise for $4 \mathrm{~h}$ in a microarray hybridisation incubator (Grant-Boekel, Cambridge, UK). Then, the slides were put in the $50 \mathrm{~mL}$ of washing buffer for $15 \mathrm{~min}$. The slides were then dipped in cold water for a few seconds and dried with compressed air. A $5 \mu \mathrm{L}$ of polyvinyl alcohol mounting medium with 1,4-diazabicyclo (2.2.2) octane (DABCO) was placed in each well, followed by a coverslip on each slide $(20 \mathrm{~mm}$; thickness no. 1; VWR, Lutterworth, UK). The slides were examined under an epifluorescence microscope (CX31; Olympus, Tokyo, Japan) using a CX-RFL-2 reflected fluorescence attachment. For each well, the number of cells from 15 different fields of view, under the microscope observation field, was counted and the average was taken as the total counted cells. The number of cells obtained was then converted into a $\log 10$ number $(\log 10$ cells/mL).

\section{Statistical analysis}

Statistical analysis was performed using IBM SPSS Statistics Software version 23. Univariate analysis of variance (ANOVA) and Duncan's test were used to determine the significant difference, where $\mathrm{p}<0.05$ is considered as statistically significant.

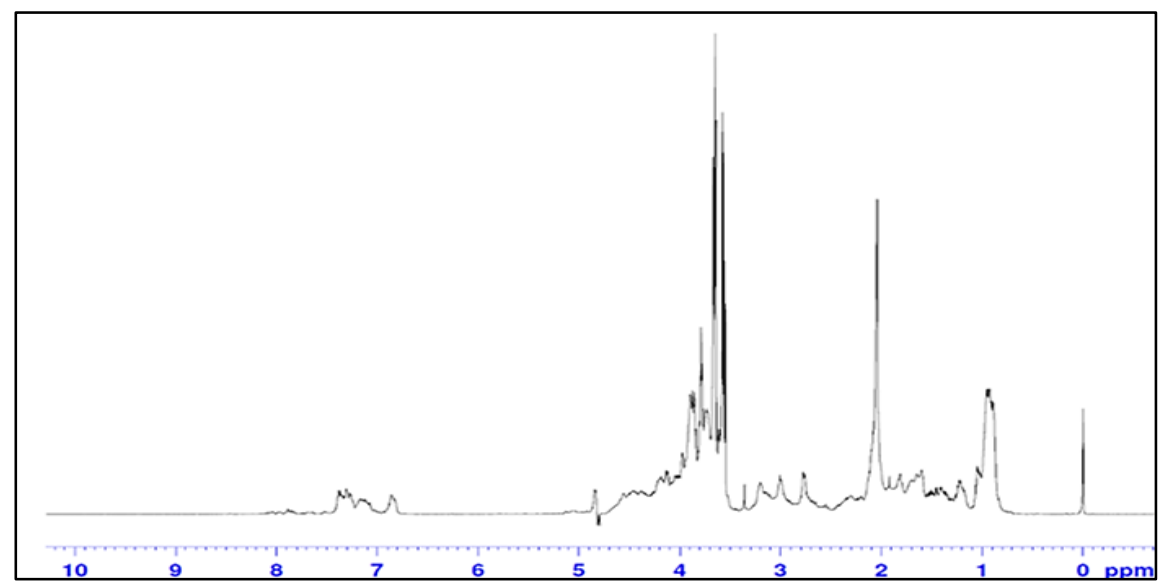

a) Signal of NMR spectroscopy with $1 \mathrm{H}$ dimension on EBN glycopeptide

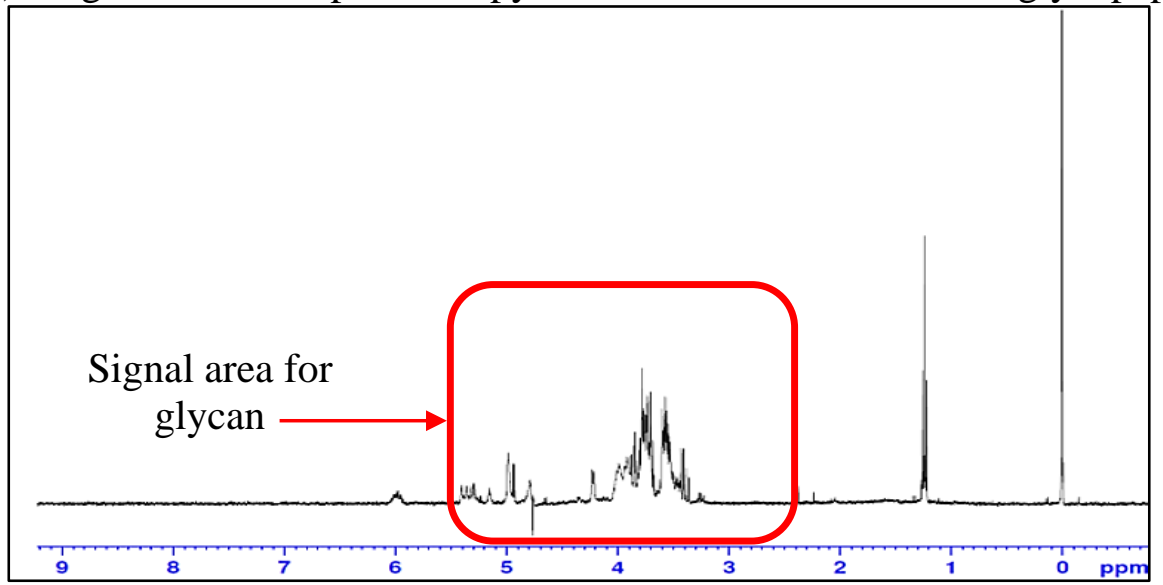

b) Signal of NMR spectroscopy with $1 \mathrm{H}$ dimension on EBN glycan sample

Figure 1. Comparison of NMR spectroscopy signal on different type of EBN compound 


\section{RESULTS AND DISSCUSION}

Observed results of the EBN glycopeptide and extracted glycan structures using NMR spectroscopy are as shown in Figure 1a and Figure 1b, respectively. Based on observations of the glycan structure bound to the antibody glycoprotein, the signals produced by the proton NMR spectroscopy was in the range of chemical shift $\delta 3.5$ to 5.3 ppm (Peng et al., 2018). According to Nguyen et al. (2016), the carbohydrate area of the herbaceous plant based on the signal produced is at a chemical shift $\delta 3.0$ to $4.2 \mathrm{ppm}$. Signals produced in other areas are signals that indicate the presence of amino acids or organic acids. Thus, the observation results obtained in this study showed that the signal from EBN extracted glycan (3.2 to $5.5 \mathrm{ppm}$ ) indicated the purity of EBN glycan sample without peptide chain, compared to the signal obtained from EBN glycopeptide. Based on the result obtained, the growth of beneficial bacteria which represented by the group of Bifidobacteria, Lactobacilli-Enterococci and Bacteroides, was improved and much stable in the presence of FOS, EBN glycopeptide and EBN glycan. The improved growth of these beneficial bacteria brought an inhibition to the potential pathogenic group of bacteria as represented by Clostridium histolyticum, as shown in Figure 2. The growth of Bifidobacteria was more significant $(p<0.05)$ in the presence of EBN glycan substrate compared to EBN glycopeptide. The suppression of the growth of Clostridium histolyticum was much better in the presence of EBN glycan than EBN glycopeptide. The results showed that the presence of oligosaccharide such as FOS and EBN glycan was much preferred by the gut bacteria as compared to the EBN glycopeptides.

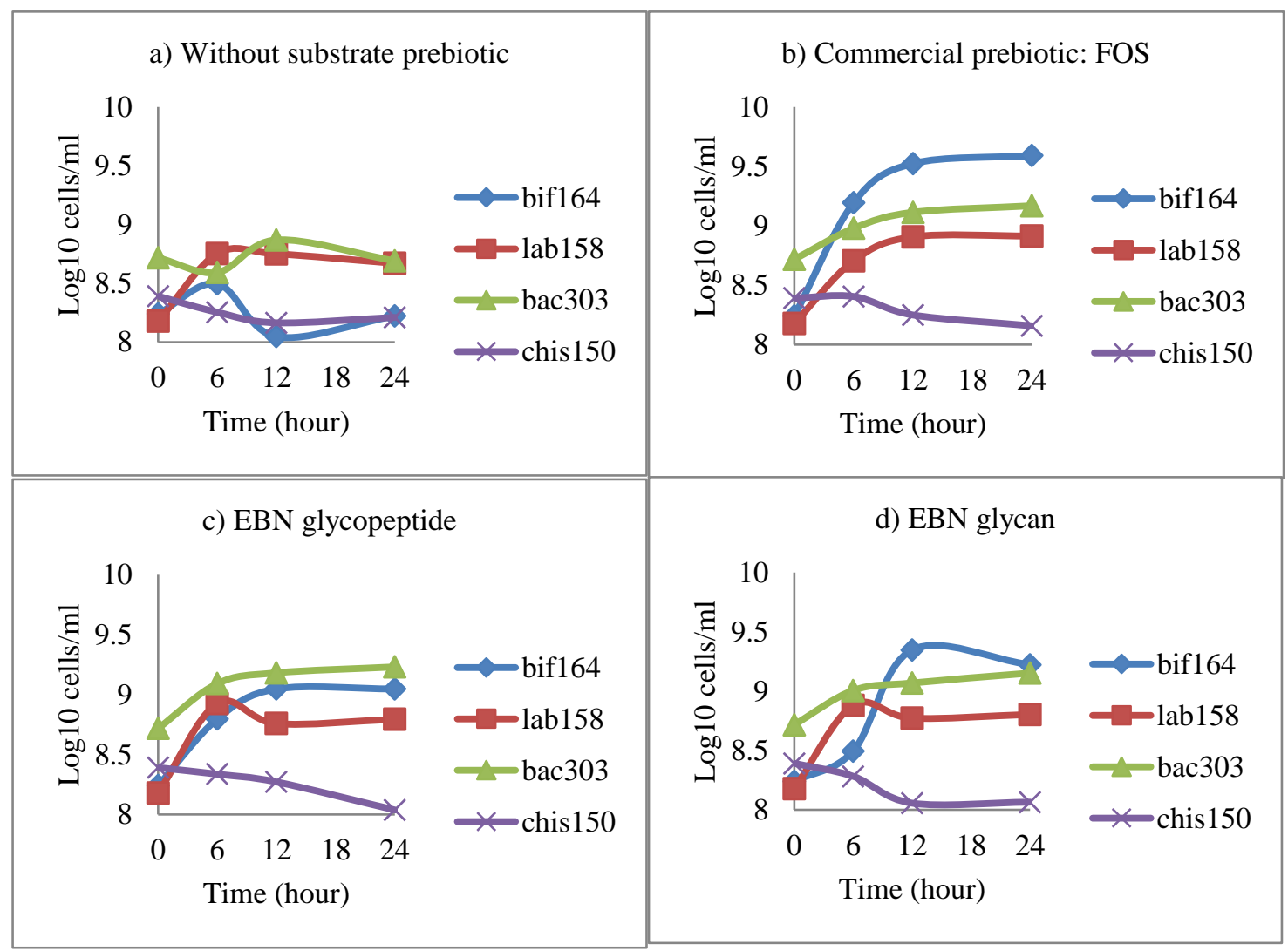

Figure 2. Growth profile of selected gut bacteria (bif164, Bifidobacterium spp.; lab158, Lactobacillus-Enterococcus; bac303, Bacteroides-Prevotella; chis150, Clostridium histolyticum) in the presence of different prebiotic substrates. 
In host-microbiota interaction, deviations from the homeostatic state can induce an imbalance microbiota condition. The imbalance microbiota has been linked to a various diseases such as diabetes, obesity, allergy diseases and colon cancer (Gholizadeh et al., 2019). Prebiotic oligosaccharides have been used to modulate enteric pathogens from causing infection to the host (Chen et al., 2017). In addition, oligosaccharide compound is usually preferred as the main substrate in the human gut microbial fermentation, although other compounds can contribute as prebiotic substrate as well (Holscher, 2017). Fermentation of the EBN compound resulted in major production of acetate and followed by propionate and butyrate as the product fermentation (Daud et al., 2019b). These short-chain fatty acid products may be carried into blood circulation and exert various kind of metabolic pathways. Acetate may involve in lipogenesis and gluconeogenesis pathways while propionate and butyrate can regulate immune function and intestinal physiology (Holscher, 2017).

In the basis of animal production, consumer and animal welfare are the main concerns prescribing the valuable alternatives of animal feed additives. Some of the alternatives that have been used as animal feed additives are enzymes, herbs, probiotics and prebiotics (Pandey et al., 2019). For example, the use of combined yeast cultivation and pectin hydrolysis as prebiotic animal feed was reported recently by Wilkowska et al. (2020).

Moreover, the ban of antibiotic growth promoters (AGPs) in animal production had increased the need to find alternative adjustment to control and prevent the colonization of pathogenic bacteria (Anadon et al., 2006). The use of prebiotic can be a safer approach to overcome the unhealthy issues which include the overuse and misuse of antibiotics in the treatment of sick animals. The overuse and misuse of antibiotics may contribute to the development of antimicrobial resistance, which is a threat to both animal and human health (Lopes et al., 2020).

Some animal studies have indicated the contributions of the gut microbiota in the production of short-chain fatty acids (SCFA), which is crucial for regulation of the gene expression in colonocytes that are related to anti-inflammatory activity, maintenance of the gut barrier function, water-electrolyte balance, and several effects on the metabolism (Cheng et al., 2018; Pan et al., 2019). Recent scientific evidences have confirmed the beneficial effect of the prebiotics on animal health, particularly in terms of protection against pathogenic bacteria and increasing the number of beneficial bacteria that may improve immune function and epithelial cell barrier functions (Azad et al., 2020).

\section{CONCLUSION}

This study had demonstrated that the EBN glycan in the form of extracted glycan and glycopeptides exhibited prebiotic activity through the colon model. The enhanced growth of the major gut beneficial bacteria such as Bifidobacteria, Lactobacilli, Enterococci and Bacteroides may lead to the stabilisation of the gut beneficial group of bacteria. The positive growth of the beneficial bacteria can strengthen the host immune system, prevent and reduce the risk of pathogenic bacterial infection. The EBN glycopeptides with prebiotic activity can be obtained by the normal EBN consumption and may be applied as functional ingredients in the food products.

\section{ACKNOWLEDGMENT}

The authors would like to thank the participating students from Universiti Putra Malaysia Campus Bintulu for their voluntary participation. This work was supported by CoE-Swiftlet Project under Grant (6371400-10301-(PN3): UPM/ST2016-013: UKM). 


\section{REFERENCES}

Amann, R., Vancanneyt, M., Schleifer, K.H., Manz, W., \& Ludwig, W. (1996). Application of a suite of $16 \mathrm{~S}$ rRNAspecific oligonucleotide probes designed to investigate bacteria of the phylum cytophaga-flavobacterbacteroides in the natural environment. Microbiology, 142(5), 1097-1106. https://doi.org/10.1099/ 13500872-142-5-1097

Anadón, A., Rosa Martínez-Larrañaga, M., \& Aranzazu Martínez, M. (2006). Probiotics for animal nutrition in the European Union. Regulation and safety assessment. Regulatory Toxicology and Pharmacology, 45(1), 91-95. https://doi.org/10.1016/j.yrtph .2006 .02 .004

Azad, M. A. K., Gao, J., Ma, J., Li, T., Tan, B., Huang, X., \& Yin, J. (2020). Opportunities of prebiotics for the intestinal health of monogastric animals. Animal Nutrition, 6(4), 379388. https://doi.org/10.1016/j.aninu. 2020.08.001

Bailey, M. T., \& Cryan, J. F. (2017). The microbiome as a key regulator of brain, behavior and immunity: Commentary on the 2017 named series. Brain, Behavior, and Immunity, 66, 18-22. https://doi.org/10.1016/ j.bbi.2017.08.017

Carlson, J. L., Erickson, J. M., Lloyd, B. B., \& Slavin, J. L. (2018). Health effects and sources of prebiotic dietary fiber. Current Developments in Nutrition, 2(3). https://doi.org/10.1093/cdn/nzy005

Chen, P., Reiter, T., Huang, B., Kong, N., \& Weimer, B. (2017). Prebiotic Oligosaccharides potentiate host protective responses against $\mathrm{L}$. Monocytogenes infection. Pathogens, 6(4), 68. https://doi.org/10.3390/patho gens6040068

Cheng, C., Wei, H., Yu, H., Xu, C., Jiang, S., \& Peng, J. (2018). Metabolic syndrome during perinatal period in sows and the link with gut microbiota and metabolites. Frontiers in Microbiology, 9(1989), 1-13. https:// doi.org/10.3389/fmicb.2018.01989

Daud, N. 'Aliah, Sarbini, S. R., Babji, A. S., Mohamad Yusop, S., \& Lim, S. J. (2019). Characterization of edible swiftlet's nest as a prebiotic ingredient using a simulated colon model. Annals of Microbiology, 69(12), 1235-1246. https://doi.org/10.1007/s13213-019-0 1507-1

Daud, N., Mohamad Yusop, S., Babji, A. S., Lim, S. J., Sarbini, S. R., \& Hui Yan, T. (2021). Edible bird's nest: physicochemical properties, production, and application of bioactive extracts and glycopeptides. Food Reviews International, 37(2), 177-196. https://doi.org/10.1080/875 59129.2019.1696359

DuBois, M., Gilles, K. A., Hamilton, J. K., Rebers, P. A., \& Smith, F. (1956). Colorimetric method for determination of sugars and related substances. Analytical Chemistry, 28(3), 350-356. https://doi.org/10. 1021/ac60111a017

Franks, A. H., Harmsen, H. J. M., Raangs, G. C., Jansen, G. J., Schut, F., \& Welling, G. W. (1998). Variations of bacterial populations in human feces measured by fluorescent in situ hybridization with group-specific $16 \mathrm{~S}$ rRNA-Targeted oligonucleotide probes. Applied and Environmental Microbiology, 64(9), 3336-3345. https://doi.org/10.1128/AEM.64.9.33 36-3345.1998

Gholizadeh, P., Mahallei, M., Pormohammad, A., Varshochi, M., Ganbarov, K., Zeinalzadeh, E., Yousefi, B., Bastami, M., Tanomand, A., Mahmood, S. S., Yousefi, M., Asgharzadeh, M., \& Kafil, H. S. (2019). Microbial balance in the intestinal microbiota and its association with diabetes, obesity and allergic disease. Microbial Pathogenesis, 127, 48-55. https:// doi.org/10.1016/j.micpath.2018.11.031 
Hermie J. M. Harmsen, P. E. (1999). A 16S rRNA-targeted probe for detection of lactobacilli and enterococci in faecal samples by fluorescent in situ hybridization. Microbial Ecology in Health and Disease, 11(1), 3-12. https: //doi.org/10.1080/089106099435862

Holscher, H. D. (2017). Dietary fiber and prebiotics and the gastrointestinal microbiota. Gut Microbes, 8(2), 172184. https://doi.org/10.1080/1949097 6.2017.1290756

Hutkins, R. W., Krumbeck, J. A., Bindels, L. B., Cani, P. D., Fahey, G., Goh, Y. J., Hamaker, B., Martens, E. C., Mills, D. A., Rastal, R. A., Vaughan, E., \& Sanders, M. E. (2016). Prebiotics: why definitions matter. Current Opinion in Biotechnology, 37, 1-7. https://doi.org/10.1016/j.copbio.2015. 09.001

Kong, Y. C., Keung, W. M., Yip, T. T., Ko, K. M., Tsao, S. W., \& Ng, M. H. (1987). Evidence that epidermal growth factor is present in swiftlet's (Collocalia) nest. Comparative Biochemistry and Physiology Part B: Comparative Biochemistry, 87(2), 221-226. https://doi.org/10.1016/030 5-0491(87)90133-7

Langendijk, P. S., Schut, F., Jansen, G. J., Raangs, G. C., Kamphuis, G. R., Wilkinson, M. H., \& Welling, G. W. (1995). Quantitative fluorescence in situ hybridization of Bifidobacterium spp. with genus-specific $16 \mathrm{~S}$ rRNAtargeted probes and its application in fecal samples. Applied and Environmental Microbiology, 61(8), 3069-3075. https://doi.org/10.1128/ AEM.61.8.3069-3075.1995

Lim, C. K. (2002). Swiftlets of Borneo: Builders of Edible Nests. Natural History Publications.

Lopes, R. B., Fausak, E. D., BernalCordoba, C., \& Silva-del-Rio, N. (n.d.). Effect of Prebiotic Supplementation on Performance and Health of Dairy Calves: Protocol for A Systematic Review and Meta-
Analysis.

Minekus, M., Alminger, M., Alvito, P., Ballance, S., Bohn, T., Bourlieu, C., Carrière, F., Boutrou, R., Corredig, M., Dupont, D., Dufour, C., Egger, L., Golding, M., Karakaya, S., Kirkhus, B., Le Feunteun, S., Lesmes, U., Macierzanka, A., Mackie, A. Brodkorb, A. (2014). A standardised static in vitro digestion method suitable for food - an international consensus. Food Funct., 5(6), 11131124. https://doi.org/10.1039/C3FO6 0702J

Nguyen, H. T., Lee, D.-K., Choi, Y.-G., Min, J.-E., Yoon, S. J., Yu, Y.-H., Lim, J., Lee, J., Kwon, S. W., \& Park, J. H. (2016). A 1 H NMR-based metabolomics approach to evaluate the geographical authenticity of herbal medicine and its application in building a model effectively assessing the mixing proportion of intentional admixtures: A case study of Panax ginseng. Journal of Pharmaceutical and Biomedical Analysis, 124, 120128. https://doi.org/10.1016/j.jpba.20 16.02 .028

Pan, J., Yin, J., Zhang, K., Xie, P., Ding, H., Huang, X., Blachier, F., \& Kong, X. (2019). Dietary xylo-oligosaccharide supplementation alters gut microbial composition and activity in pigs according to age and dose. $A M B$ Express, 9(1), 1-10. https://doi.org/ 10.1186/s13568-019-0858-6

Peng, J., Patil, S. M., Keire, D. A., \& Chen, K. (2018). Chemical structure and composition of major glycans covalently linked to therapeutic monoclonal antibodies by middledown nuclear magnetic resonance. Analytical Chemistry, 90(18), 1101611024. https://doi.org/10.1021/acs.an alchem.8b02637

Sarbini, S. R., Kolida, S., Naeye, T., Einerhand, A., Brison, Y., RemaudSimeon, M., Monsan, P., Gibson, G. R., \& Rastall, R. A. (2011). In vitro fermentation of linear and $\alpha-1,2-$ 
branched dextrans by the human fecal microbiota. Applied and Environmental Microbiology, 77(15), 5307-5315. https://doi.org/10.1128/A EM.02568-10

Singla, V., \& Chakkaravarthi, S. (2017). Applications of prebiotics in food industry: A review. Food Science and Technology International, 23(8), 649667. https://doi.org/10.1177/1082013 217721769

Tailford, L. E., Crost, E. H., Kavanaugh, D., \& Juge, N. (2015). Mucin glycan foraging in the human gut microbiome. Frontiers in Genetics, 6, 81. https://doi.org/10.3389/fgene.201 5.00081

Wilkowska, A., Berlowska, J., Nowak, A., Motyl, I., Antczak-Chrobot, A., Wojtczak, M., Kunicka-Styczyńska, A., Binczarski, M., \& Dziugan, P. (2020). Combined yeast cultivation and pectin hydrolysis as an effective method of producing prebiotic animal feed from sugar beet pulp. Biomolecules, 10(5), 724. https://doi. org/10.3390/biom10050724 